УДК 621.391

Олександр Миколайович Нестеров

Національний університет оборони Украӥни імені Івана Черняховського, Київ, Украӥна

\title{
УДОСКОНАЛЕНИЙ МЕТОД РОЗРАХУНКУ ПРОПУСКНОЇ СПРОМОЖНОСТІ СИСТЕМИ ЗВ'ЯЗКУ СПЕЦІАЛЬНОГО ПРИЗНАЧЕННЯ НА ІНФОРМАЦІЙНИХ НАПРЯМКАХ
}

\begin{abstract}
Одним з найбільш актуальних наукових завдань у галузі військового управління під час ведення операції для системи зв 'язку спеціального призначення є передавання інформаџії в рељсимі реального часу з дотриманням низки вимог щзодо якості обслуговування. Це пов'язано із тим, ще множсна потоків даних передається по мережі, ресурси якої необхідно розподілити між циими потоками за певною пропориією.

Оскільки дані, які підлягають передаванню, різні за своєю природою та важливістю, то необхідно мати механізми, які дають змогу розв'язувати задачу розподілу ресурсів оперативно, у відповідності до властивостей тих потоків, які передаються у конкретний момент часу через конкретні вузли спеціального призначення. Такі механізми для органів планування системи зв'язку спеціального призначення повинні базуватись на удосконалених методах розподілу ресурсів, щзо мають високу масштабованість, швидкодію, гнучкість, низьку операчійну складність та ресурсоємність.
\end{abstract}

Ключові слова: система зв'язку спеціального призначення; система управління; інформачійний напрямок; інформаційна система; канал зв'язку; пропускна спроможність; автоматизована система управління.

Вступ

Постановка проблеми. Роботи, які присвячені методам оцінки пропускної спроможності, здебільшого, носять теоретичний характер та спрямовані на створення нових алгоритмів управління потоками інформації, що робить їх важко реалізованими в реальній системі зв'язку спеціального призначення. Іншим недоліком існуючих методів $\epsilon$ використання комплексного підходу до оцінювання пропускної спроможності інформаційних напрямків без урахування особливостей кожного типу трафіку, що генерується різними мережевими додатками.

Зменшення затримок в обслуговуванні інформаційних потоків частково досягається шляхом вдосконалення технічної складової наприклад використанням обладнання 3 більшим об'ємом буферної пам'яті, але цей підхід $є$ неприйнятним при передаванні інформації в режимі реального часу.

Аналіз останніх досліджень і публікацій. При створені систем зв'язку спеціального призначення нового покоління виникає проблема розрахунку пропускної спроможності. Існуючий науковометодичний апарат визначення пропускної спроможності системи спеціального призначення за наведеним показником застарів [1], розроблений ще за часів СРСР, орієнтований на застосування аналогових засобів зв'язку. На практиці при визначенні пропускної спроможності використовують математичне моделювання, або, без належного обгрунтування, традиційні формули теорії розподілення інформації [2-5]. Аналітичне вирішення для технологій нового покоління, запропонованих в [6], надзвичайно громіздкі i практично не застосовуються. Загальноприйнятого аналітичного або інженерного способу вирішення проблеми для систем спеціального призначення на сьогодні немає. Такий стан речей в подальшому може привести до зниження ефективності оперативного планування системи спеціального призначення в процесі управління військами (силами)

Мета статті. Удосконалити метод розрахунку пропускної спроможності системи спеціального призначення на інформаційних напрямках для оперативності процесу планування системи зв'язку спеціального призначення.

\section{Виклад основного матеріалу} дослідження

Показником ефективності, який найбільш повно характеризує систему зв'язку спеціального призначення 3 точки зору виконання покладених на неї завдань, є виконане навантаження, яке оцінюється як за напрямками зв'язку, так і у всій мережі в цілому $\mathrm{У}$ той же час різко збільшилася кількість інформації необхідної для здійснення управління військами. Для доставки інформації широко використовуються сучасні телекомунікаційні сервіси (IP-телефонія, передача даних, IP-відеозв'язок, тощо), що призводить до підвищення вимог до обсягу і якості транспортної мережі передачі даних та часто призводить до невиправдано високих витрат на використання устаткування із завищеними вимогами до його технічних характеристик, утримання не потрібного обладнання та особового складу, надлишкову оренду цифрового ресурсу 3 телекомунікаційної мережі загального користування. При розгортанні вузів спеціального призначення (ВСП) в інтересах органів управління необхідно враховувати різноманітні джерела трафіку, що циркулює у мережі C4ISR (Comand, Control, Communication and Computers System upgrade): інформаційний обмін між базами даних, файловий документообіг, IP-телефонію і IPвідеозв'язок, інформації від сенсорної мережі тощо. Кожен вид трафіку пред'являє свої вимоги до якості транспортної мережі та показника пропускної спроможності. У той же час для розрахунку пропускної спроможності мережі широко використовується примітивний метод, заснований на 
простому арифметичному підсумовуванні потоків даних від різних джерел 3 урахуванням емпіричного «коефіцієнта вибухового трафіку» [7]. При цьому відбувається підсумовування пропускної спроможності ліній зв'язку знизу до гори відповідно до структури типу “дерево” без кореневої гілки [1,3], що відповідає структурі системи управління.

Запропонована у [7] методика призначена для роботи органів управління зв'язком для вибору найбільш оптимального (раціонального) варіанту розгортання системи зв'язку спеціального призначення, що планується. При цьому вважається, що система зв'язку спеціального призначення будується 3 використанням цифрових каналів та мереж та має деревоподібну структуру.

Вихідними даними для розрахунку пропускної спроможності в такому випадку повинні бути: пропускні спроможності всіх каналів зв'язку первинної мережі (ліній зв'язку та прив'язки) на інформаційних напрямках; мінімально необхідні пропускні спроможності для роботи кінцевих засобів (телефон, передача даних, відеконференцзв'язок) зв'язку та їх кількість на пункті управління.

Кількісним показником оцінки пропускної спроможності системи зв'язку є швидкість передачі даних в каналах (лініях) зв'язку, що забезпечує визначений перелік інформаційних послуг (сервісів) із заданою якістю зв'язку. У свою чергу, якість зв'язку досягається забезпеченням мінімально необхідної пропускної спроможності, що забезпечить функціонування певної послуги (сервісу).

В основі методу закладена оцінка пропускної спроможності цифрових каналів та мереж. При цьому використовується метод декомпозиції: вся система зв'язку спеціального призначення у розбивається на інформаційні напрямки від старшого ВСП (в інтересах якго здійснюється оцінка системи) до підлеглих ВСП. Розрахункам підлягають всі інформаційні напрямки, а висновок щодо їх функціонування робиться окремо.

Пропускна спроможність цифрових мереж (каналів) на інформаційних напрямках повинна забезпечувати інформаційний обмін всіх користувачів телекомунікаційних сервісів, які використовують даний канал (під сервісами розуміється телефонія, передача даних від АРМ, відеоконференцзв'язок). Вимоги щодо забезпечення необхідної (заданої) якості зв'язку виконуються у випадку підтримання мінімальної швидкості передачі інформації для даного сервісу.

Наведемо запропонований метод аналітичними виразами, що не зроблено у [7]. Врахуємо наявність на пунктах управління декількох мереж передачі даних. Це мережі - мережа відкритої інформації, мережа обміну службовою інформацією та захищена система обміну інформацією. Значення пропускної спроможності для певного сервісу визначається як добуток середнього значення швидкості передачі даних кожного із сервісів та кількості терміналів (робочих місць) кожного сервісу. Сумарна пропускна спроможність $C_{\text {необх }}$ буде мати вигляд:

$$
\mathrm{C}_{\text {необ }}=\sum_{\mathrm{i}=1}^{\mathrm{I}} \mathrm{k}_{\mathrm{i}} \mathrm{C}_{\mathrm{i}}+\sum_{\mathrm{j}=1}^{\mathrm{J}} \mathrm{k}_{\mathrm{j}} \mathrm{C}_{\mathrm{j}}+\sum_{\mathrm{y}=1}^{\mathrm{Y}} \mathrm{k}_{\mathrm{y}} \mathrm{C}_{\mathrm{y}}+\sum_{\mathrm{r}=1}^{\mathrm{R}} \mathrm{k}_{\mathrm{r}} \mathrm{C}_{\mathrm{r}}
$$

де: $\mathrm{C}_{\mathrm{i}}-$ середнє значення швидкості передачі даних $i$-го сервісу VoIP телефоніі;

$\mathrm{C}_{\mathrm{j}}$ - середнє значення швидкості передачі даних j-го сервісу відеоконференц зв'язку;

$\mathrm{C}_{\mathrm{y}}$ - середнє значення швидкості передачі даних y- електронної пошти;

$\mathrm{C}_{\mathrm{r}}$ - середнє значення швидкості передачі даних $r$-з камер відео спостереження;

$\mathrm{k}_{\mathrm{i}}$ - кількості терміналів (робочих місць) сервісів VoIP телефонії;

$\mathrm{k}_{\mathrm{j}}$ - кількості терміналів (робочих місць) сервісів відеоконференц зв'язку;

$\mathrm{k}_{\mathrm{y}}$ - кількості терміналів (робочих місць) сервісів електронної пошти;

$\mathrm{k}_{\mathrm{r}}$ - кількості терміналів (робочих місць) сервісів відео спостереження.

Наведений вираз буде справедливим при використанні стандартизованих швидкостей передачі даних для кожного із сервісів, що забезпечується на пункті управління. Проте, застосування стандартизованих швидкостей описує ідеальний випадок та буде рідко зустрічатися на практиці. Тому доцільно перейти до підсумовування різних швидкостей передачі даних для кожного із сервісів:

$$
\begin{aligned}
\mathrm{C}_{\text {необх }} & =\sum_{\mathrm{i}=1}^{\mathrm{I}} \sum_{\mathrm{k}_{\mathrm{i}}=1}^{\mathrm{K}_{\mathrm{i}}} \mathrm{C}_{\mathrm{i}}+\sum_{\mathrm{j}=1}^{\mathrm{J}} \sum_{\mathrm{k}_{\mathrm{j}}=1}^{\mathrm{K}_{\mathrm{j}}} \mathrm{C}_{\mathrm{j}}+ \\
+ & \sum_{\mathrm{y}=1 \mathrm{k}_{\mathrm{y}}=1}^{\mathrm{I}} \sum_{\mathrm{y}}^{\mathrm{K}_{\mathrm{y}}} \mathrm{C}_{\mathrm{y}}+\sum_{\mathrm{r}=1}^{\mathrm{R}} \sum_{\mathrm{k}_{\mathrm{r}}=1}^{\mathrm{K}_{\mathrm{r}}} \mathrm{C}_{\mathrm{r}},
\end{aligned}
$$

де: $\mathrm{k}_{\mathrm{i}}=1 \ldots \mathrm{K}_{\mathrm{i}}-$ кількості терміналів

(робочих місць) сервісів VoIP телефонії;

$\mathrm{k}_{\mathrm{j}}=1 . . . \mathrm{K}_{\mathrm{j}}$ - кількості терміналів

(робочих місць) сервісів відеоконференцзв'язку;

i = 1... I - кількість сервісів VoIP телефонії;

$\mathrm{j}=1 \ldots \mathrm{J}$ - кількість сервісів відеоконференц зв'язку;

y = 1... Y - кількість сервісів електронної пошти;

$\mathrm{r}=1 \ldots \mathrm{R}$ - кількість сервісів відео спостереження;

$\mathrm{C}_{\mathrm{i}}-$ значення швидкості передачі даних $i$-го сервісу VoIP телефоніі;

$\mathrm{C}_{\mathrm{j}}$ - значення швидкості передачі даних $j$-го сервісу відеоконференц зв'язку;

$\mathrm{C}_{\mathrm{y}}$ - значення швидкості передачі даних $y$-го сервісу електронної пошти;

$\mathrm{C}_{\mathrm{r}}$ - значення швидкості передачі даних $r$-го сервісу відео спостереження.

Запропонований підхід, також не $\epsilon$ досконалим, та потребує подальшого удосконалення за рахунок введення у вирази (1), (2) пропускних спроможностей необхідних для сталого функціонування інформаційних систем, автоматизованих систем управління та сенсорних мереж. 3 урахуванням запропонованого вираз (1) можливо переписати до вигляду:

$$
\begin{gathered}
\mathrm{C}_{\text {необ }}=\sum_{\mathrm{i}=1}^{\mathrm{I}} \mathrm{k}_{\mathrm{i}} \mathrm{C}_{\mathrm{i}}+\sum_{\mathrm{j}=1}^{\mathrm{J}} \mathrm{k}_{\mathrm{j}} \mathrm{C}_{\mathrm{j}}+\sum_{\mathrm{y}=1}^{\mathrm{Y}} \mathrm{k}_{\mathrm{y}} \mathrm{C}_{\mathrm{y}}+ \\
+\sum_{\mathrm{r}=1}^{\mathrm{R}} \mathrm{k}_{\mathrm{r}} \mathrm{C}_{\mathrm{r}}++\sum_{\mathrm{f}=1}^{\mathrm{F}} \mathrm{k}_{\mathrm{f}} \mathrm{C}_{\mathrm{f}}+\sum_{\mathrm{g}=1}^{\mathrm{G}} \mathrm{k}_{\mathrm{g}} \mathrm{C}_{\mathrm{g}}+\sum_{\mathrm{h}=1}^{\mathrm{H}} \mathrm{k}_{\mathrm{h}} \mathrm{C}_{\mathrm{h}} .
\end{gathered}
$$


де $\mathrm{C}_{\mathrm{i}}$ - середнє значення швидкості передачі даних сервісу VoIP телефонії;

$\mathrm{C}_{\mathrm{j}}$ - середне значення швидкості передачі даних відеоконференц зв'язку;

$\mathrm{C}_{\mathrm{y}}$ - середнє значення швидкості передачі даних електронної пошти;

$\mathrm{C}_{\mathrm{r}}$ - середнє значення швидкості передачі даних 3 камер відео спостереження;

$\mathrm{C}_{\mathrm{f}}$ - середнє значення швидкості передачі даних в інформаційній системі;

$\mathrm{C}_{\mathrm{g}}$ - середнє значення швидкості передачі даних в автоматизованій системі управління;

$\mathrm{C}_{\mathrm{h}}$ - середнє значення швидкості передачі даних у сенсорній мережі.

Наведений вираз не у повній мірі відображає реальний стан справ. На практиці не можлива ситуація коли значення пропускної спроможності для інформаційних систем, автоматизованих систем управління та сенсорних мереж будуть однаковими. Тому доцільно перейти до виразу (2) та записати його у вигляді виразу:

$$
\begin{gathered}
\mathrm{C}_{\text {необ }}=\sum_{\mathrm{i}=1}^{\mathrm{I}} \sum_{\mathrm{k}_{\mathrm{i}}=1}^{\mathrm{K}_{\mathrm{i}}} \mathrm{C}_{\mathrm{i}}+\sum_{\mathrm{j}=1 \mathrm{k}_{\mathrm{j}}=1}^{\mathrm{J}} \sum_{\mathrm{j}}^{\mathrm{K}_{\mathrm{j}}} \mathrm{C}_{\mathrm{j}}+\sum_{\mathrm{y}=1 \mathrm{k}_{\mathrm{y}}=1}^{\mathrm{I}} \sum_{\mathrm{y}}^{\mathrm{K}_{\mathrm{y}}} \mathrm{C}_{\mathrm{y}}+\sum_{\mathrm{r}=1 \mathrm{k}_{\mathrm{r}}=1}^{\mathrm{R}} \sum_{\mathrm{r}}^{\mathrm{K}_{\mathrm{r}}} \mathrm{C}_{\mathrm{r}}+ \\
+\sum_{\mathrm{f}=1 \mathrm{k}_{\mathrm{f}}=1}^{\mathrm{F}} \sum_{\mathrm{f}}^{\mathrm{K}_{\mathrm{f}}} \mathrm{k}_{\mathrm{f}} \mathrm{C}_{\mathrm{f}}+\sum_{\mathrm{g}=1 \mathrm{k}_{\mathrm{g}}=1}^{\mathrm{G}} \sum_{\mathrm{g}}^{\mathrm{K}_{\mathrm{g}}} \mathrm{k}_{\mathrm{g}} \mathrm{C}_{\mathrm{g}}+\sum_{\mathrm{h}=1 \mathrm{k}_{\mathrm{h}}=1}^{\mathrm{H}} \sum_{\mathrm{h}}^{\mathrm{K}_{\mathrm{h}}} \mathrm{k}_{\mathrm{h}} \mathrm{C}_{\mathrm{h}} .
\end{gathered}
$$

де: $\mathrm{C}_{\mathrm{i}}$ - значення швидкості передачі даних $i$-го сервісу VoIP телефонії;

$\mathrm{C}_{\mathrm{j}}$ - значення швидкості передачі даних $j$-го сервісу відеоконференц зв'язку;

$\mathrm{C}_{\mathrm{y}}$ - значення швидкості передачі даних $y$-го сервісу електронної пошти;

$\mathrm{C}_{\mathrm{r}}$ - значення швидкості передачі даних $r$-го сервісу відео спостереження.

$\mathrm{C}_{\mathrm{f}}$ - значення швидкості передачі даних в $f$-ній інформаційній системі;

$\mathrm{C}_{\mathrm{g}}$ - значення швидкості передачі даних в $g$-й автоматизованій системі управління;

$\mathrm{C}_{\mathrm{h}}$ - значення швидкості передачі даних у $h$-й сенсорній мережі.

Запропонований підхід не надає уявлення про загальну пропускну спроможність мережі i розрахований на отримання сумарної швидкості передачі всіх абонентських пристроїв на пункті управління. При цьому сенсорні мережі розглядаються як кінцеві пристрої віртуально розміщені на пункті управління. Вирази $(1-4)$ можливо застосувати лише для визначення пропускної спроможності ВСП найнижчої ланки управління, який не має подальших з'єднань вниз. Фізично - це пропускна спроможність маршрутизатора ВСП пункту управління.

Відповідно до методу [7], пропускна спроможність лінії зв'язку, що поєднує ВСП нижчої ланки управління 3 вищим вузлом повинна відповідати виразу:

$$
\mathrm{C}_{\text {лз }} \geq 1,2 \mathrm{C}_{\text {необх }} \text {. }
$$

Виразом (5) передбачається 20-ти відсоткове резервування пропускної спроможності лінії зв'язку порівняно 3 розрахунковою пропускною спроможністю ВСП.

Пропускна спроможність наступного у системі iєрархії ВСП буде складатися як сума пропускної спроможності абонентських пристрої ВСП та ліній прямого зв'язку, які до нього підключені від нижчої ланки управління. У випадку, що описується, буде мати місце паралельне з'єднання ВСП. Відповідно [7], сумарна пропускна спроможність буде мати вираз:

$$
\mathrm{C}_{\sum \text { лз }}=\sum_{\mathrm{s}=1}^{\mathrm{S}} \mathrm{C}_{\text {лз } \mathrm{s}} \text {. }
$$

де $\mathrm{s}=1 \ldots ., \mathrm{S}-$ лінії зв'язку від нижчих пунктів управління.

Таким чином, пропускна спроможність ВСП ротного опорного пункту буде виглядати як сума пропускної спроможності абонентських пристроїв ВСП та трьох ліній зв'язку з підлеглими взводними опорними пунктами:

$$
\begin{gathered}
\mathrm{C}=\sum_{\mathrm{i}=1}^{\mathrm{I}} \sum_{\mathrm{k}_{\mathrm{i}}=1}^{\mathrm{K}_{\mathrm{i}}} \mathrm{C}_{\mathrm{i}}+\sum_{\mathrm{j}=1}^{\mathrm{J}} \sum_{\mathrm{k}_{\mathrm{j}}=1}^{\mathrm{K}_{\mathrm{j}}} \mathrm{C}_{\mathrm{j}}+\sum_{\mathrm{y}=1 \mathrm{k}_{\mathrm{y}}=1}^{\mathrm{I}} \sum_{\mathrm{y}}^{\mathrm{K}_{\mathrm{y}}} \mathrm{C}_{\mathrm{y}}+\sum_{\mathrm{r}=1}^{\mathrm{R}} \sum_{\mathrm{k}_{\mathrm{r}}=1}^{\mathrm{K}_{\mathrm{r}}} \mathrm{C}_{\mathrm{r}}+ \\
+\sum_{f=1}^{F} \sum_{k_{f}=1}^{K_{f}} k_{f} C_{f}+\sum_{g=1}^{G} \sum_{k_{g}=1}^{K_{g}} k_{g} C_{g}+\sum_{h=1}^{H} \sum_{k_{h}=1}^{K_{h}} k_{h} C_{h}+\sum_{s=1}^{S} C_{l 3 s}
\end{gathered}
$$

Для спрощення аналітичних виразів та формалізації методу визначення пропускної спроможності введемо алгоритм розрахунку пропускної спроможності. На першому етапі проводиться розрахунок пропускної спроможності ВСП пунктів управління за встановленими абонентськими пристроями на робочих місцях посадових осіб та наданими сервісами. На наступних етапах необхідно підсумовувати пропускну спроможність ВСП пунктів управління з урахуванням кількості підключених ліній прямого зв'язку від нижчих пунктів управління.

\section{Висновки й перспективи подалыших} досліджень

Наведений удосконалений метод розрахунку пропускної спроможності дозволяє здійснювати оцінку системи зв'язку спеціального призначення під час оперативного планування.

Відрізняється від відомих урахуванням використання цифрових мереж (каналів) та простотою використання, що дозволяє використовувати іiі для оперативного планування системи зв'язку спеціального призначення.

Удосконалений метод розрахунку пропускної спроможності системи зв'язку спеціального призначення показав, що напрямком подальшого дослідження $\epsilon$ удосконалення науково-методичного апарату з питань оцінки ефективності функціонування системи зв'язку спеціального призначення за пропускною спроможністю.

Подальші дослідження будуть направлені на розробку методів (методик) удосконалення процесу оперативного планування систем зв'язку спеціального призначення. 


\section{Лimepamypa}

1. Методики по расчету и оценке полевых систем связи // Курс лекций. - Л. : ВАС, 1985. 2. Корнишев Ю.Н. Теорія розподілення інформації / Ю.Н. Корнишев, Г.Л.Фань СПб.: ХВ-Петербург, 2005. - 288 с. 3. Боговик А. В. Эффективность систем военной связи и методы ее оценки / А. В. Боговик, В. В. Игнатов - СПб.: ВАС, 2006. - 183 с. 4. Величко В.В. Телекоммуникационные системы и сети / В.В. Величко, Е.А. Субботин, В.П. Шувалов, А.Ф. Ярославцев. - Т. 3. Мультисервисные сети. - М.: Горячая линия - Телеком, 2005. - 592 с. 5. Шнепс М.А. Системы распределения информации. Методы расчета: Справочное пособие. М.:Связь, 1979. - 312 с. 6. Ершов В.А. Метод расчета пропускной способности звена Ш-ЦСИС с технологией АТМ при мультисервисном обслуживании /В.А. Ершов, Э.Б. Ершова, В.В. Ковалев // Электросвязь. 2000. - № 3. - С. 20-23. 7. Остапчук В.М. Методика оцінки пропускної спроможності як характеристики системи військового зв'язку/ В.М. Остапчук, С.І. Фараон, Л.О. Бондаренко Сучасні інформаційні технології у сфері безпеки та оборони. - 2018. - №1(31). - С. 81 - 84 .

\title{
УСОВЕРШЕНСТВОВАННЫЙ МЕТОД РАСЧЕТА ПРОПУСКНОЙ СПОСОБНОСТИ СИСТЕМЫ СВЯЗИ СПЕЦИАЛЬНОГО НАЗНАЧЕНИЯ НА ИНФОРМАЦИОННЫХ НАПРАВЛЕНИЯХ
}

\author{
Александр Николаевич Нестеров
}

\section{Национальный университет обороны Украины имени Ивана Черняховского, Киев, Украина}

Одним из наиболее актуальных научных задач в области военного управления при ведении операчии для системы связи специиального назначения является передача информации в режиме реального времени с соблюдением ряда требований к качеству обслуживания. Это связано с тем, что множество потоков данньх передается по сети, ресурсы которой необходимо распределить между этими потоками по определенной пропоричи.

Поскольку данные, которые подлежат передаче, различные по своей природе и важности, то необходимо иметь механизмы, которые позволяют решать задачу распределения ресурсов оперативно, в соответствии с свойств тех потоков, которые передаются в конкретный момент времени через конкретные узль спеииального назначения. Такие механизмы для органов планирования системы связи спечиального назначения должны базироваться на усовершенствованных методах распределения ресурсов, имеюших высокую масттабируемость, быстродействие, гибкость, низкую операционную сложность и ресурсоемкость.

Ключевые слова: система связи специального назначения; система управления; информационное направление; информационная система; канал святи; пропускная способность; автоматизированная система управления.

\section{THE ENHANCED METHOD OF CAPACITY COMPUTATION FOR THE SPECIAL-FORCES COMMUNICATION SYSTEM IN INFORMATION DIRECTIONS}

\section{Oleksandr Nesterov}

\section{National Defence University of Ukraine named after Ivan Cherniakhovsky, Kyiv, Ukraine}

One of the most actual scientific challenges in the area of military command while conducting an operation for the special-purpose communication system is the real-time data transmission in accordance with requirements for the service quality standards. This is because a great number of data flows are transmitted through the network, whose resource has to be apportioned between those flows.

As the data to be transmitted differ in their nature and significance the mechanisms are necessary which should solve the problem of allocating the resource promptly and in accordance with characteristics of the data flows being transmitted at a specific point of time through the specific special-purpose nodes. Such mechanisms for the authorities planning the special-purpose communications systems have to be based on the enhances methods of resource allocation having high-degree scalability, operating speed, flexibility, low operating complexity and resource intensity.

Keywords: special-purpose communication system, control (command) system. Information direction, information system, channel communication, capacity, automated control system.

\section{References}

1. Methods for calculating and evaluating field communication systems // Course of lectures. - L.: YOU, 1985. 2. Kornishev Yu.N. Theory of Information and Information / Yu.N. Kornishev, G.L. Fan - St. Petersburg: HV-Petersburg, 2005 --- 288 p. 3. Bogovik A. V. The effectiveness of military communications systems and methods for its evaluation / A. V. Bogovik, V. V. Ignatov - St. Petersburg: VAS, 2006. - 183 p. 4. Velichko V.V. Telecommunication systems and networks / V.V. Velichko, E.A. Subbotin, V.P. Shuvalov, A.F. Yaroslavtsev. - T. 3. Multiservice networks. - M .: Hot line - Telecom, 2005 .- 592 p. 5. Shneps
M.A. Information distribution systems. Calculation methods: Reference manual. M.: Communication, 1979.- 312 p. 6. Ershov V.A. The method for calculating the bandwidth of the Sh-ISDN link with ATM technology for multiservice service / B.A. Ershov, E.B. Ershova, V.V. Kovalev // Telecommunication. - 2000. - No. 3. - S. 20-23. 7. Ostapchuk V.M. Methodology for assessing throughput capacities as a characteristic of a system of voice feedback / V.M. Ostapchuk, S.I. Pharaoh, L.O. Bondarenko Advanced Information Technology in the field of security and defense. - 2018. - No. 1 (31). S. 81-84. 